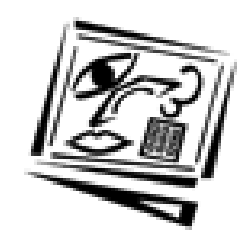

Australian Journal of Educational Technology

\title{
Education, media and the locus of control
}

\author{
Peter Blakey \\ Australian Catholic University \\ P.Blakey@mary.acu.edu.au
}

I would like to present some thoughts based largely on my experiences as a long term student and a minor technocrat. I would like to discuss the nature of who controls what, in the presentation and by implication the content of what is learned, and how this will effect the nature and content of learning, given the increase in technological activity in this field.

To commence with, I refer to matters raised by Geoffrey Roberts (Roberts 1993), about the design of major auditoriums for use in lecturing to 300500 students in universities. How can they see and read the notes from the overhead projector, and why a video projector attached to a computer provides a better image. Balance this against the story David Loader (Loader 1994), Principal of Methodist Ladies College, Kew Victoria, tells about how their network manager wanted to introduce censoring devices in their network, so that the "little ladies" would not use the type of language they did, in their email correspondence between themselves, whilst working in class. Or the UNESCO report by Susan Stuebings (Stuebings, 1994), that examined twenty-first century classrooms, and wondered whether they weren't a thing of the past.

These are some of the problems that are confronted by the technologist endeavouring to meet client needs, whilst both operating under a pittance of a budget and also trying to adapt classroom techniques of overhead projector and one way information delivery to this environment.

What is becoming obvious, however, given the capacities of the technologies, both present and anticipated, is that learning is becoming both a personal and participative activity. It is no longer something that requires a group activity, in which participation is limited to the immediate social interaction. The limits of the equipment in use and the user's initiative govern how, what and when learning occurs.

This presents educators with a number of issues which effect how education can occur, and how the evidence of its presence can be seen. (A 
cute definition of evaluation). The first most obvious thing that these changes provoke, or can provoke, is activity. The sense of the new, in which fun and motivation rather the Protestant moral ethic of "this is good for you, even though it may be boring" to paraphrase a number of scholars, drives the learning activities. Choice abounds, as we all come to terms with the "brave new world" of electronic network communication.

An appreciation of the learned or the known is rather difficult to simply define. There needs to be evidence that there is more than immediate memory retention, and that what effort that has been applied is evidenced in the activities rather than recorded responses. The range of options extend the locus of control, away from the traditional teacher-directed, institutionally driven model to a potentially less focused model of learning. Curriculum design becomes more nebulous as the access to information without a consensus of priority, of what needs to be known, presents the student with additional challenges that their teacher/lecturers may not be prepared to allow.

There is a simple example of this. A student using their electronic access facilities researches a literary text. The text could be modern, or it could be of a deceased author, but the student contacts the relevant scholars and (perhaps) the author, as part of the work. The information and the synthesis of the research producing a series of conclusions that do not necessarily fit into the conventional view of the text under discussion. Assessment arrives, and the result is disputed. How is either position defensible? Should, or is it possible to expect the academic running the course to know that there has been a "phase shift in opinion" on the text, and that insights have been made in the course of its "re-reading" that differ from "conventional thought on the subject".

Given the nature of present academic/student relations - where the academic is seen to some extent as the source of information and the student the seeker; where there is an institutional authority with the former, that may not be questioned by the latter?

The present means of verification through bibliographic notation may not be enough to provide the support to the student's claims and the truth could become ignored or dismissed within an effort to maintain a status quo. The motivation to learn is lost, and the scholar soon complains that the student only recycles old information without seeking and developing their understanding of the area of study.

This I grant may appear overstated, but in view of the degree of access the Internet and the World Wide Web now provide, may not be as much as would appear. Marriott and Brittain (1994), in their research into the establishment of an electronic journal (one that comes on the Internet or World Wide Web, and not one that sells amplifiers etc.) found that defining what was content, in terms germane to the sciences of 
information management (another term for library studies) was becoming increasingly difficult. Topics that appeared as immediate text could become doorways to bodies of information that ranged from movies through to additional bodies of text. The information rather than being linear, as in before the reader, and interpreted within the immediate context of itself, became a content point that opened up on additional information germane to that topic rather shall simply part of the information on the screen.

Confused? Stick around.

The relevance of the example is that information is now no longer in packages that can be previewed, verified and catalogued. Information is available at call, and it is no longer possible for the pedagogical academic to keep up, let alone lead in the sense of knowing more. Access denies the ownership, and therefore the power that the 'knowing" once had. The role of the teacher and academic changes, and with it the demands on the student. Both must become seekers and lead each other on.

The issues that develop from the situations described are: Who defines what is to be learned?

- How is equity maintained so that the information and knowledge can be acquired and used?

- What is done with the information?

- How, who or what determines relevance of the knowledge acquired?

In determining what is to be learned, curriculists in the past have been able to regulate the flow of knowledge and verify its existence within the student. Year One children were not taught calculus, but second year university students may be taught how to teach it. Knowledge is seen within this regime as having both a hierarchical complexity, and applied relevance.

Year One children need to know how to spell and to count, not how theories effect the movement of a mythical (or imaginary) moving point. Relevance being determined by those who have the 'knowledge' based on research that others have done, in an effort to improve the existing model.

Along comes an increased access to diverse bodies of information, as well as a means of finding more about anything, and capacity to monitor and regulate diminishes. The lack of central control, an expressed design component of the structure, makes it impossible to regulate content, except through mutual consent or coordinated action. Thus with the lack of an administrating force governing the content, and its flow, information flow becomes less linear and relies on the user to make the judgements as to what shall be part of the learning experience. 
The point I am driving at is that without an in-built support, learning focus and defined relevance within the situation becomes difficult. The information does discriminate and the initial curiosity could move in time to information overload.

Such controls as exist relate not so much to administration or management in the first instance, but equipment access, line access and capacity to connect, understand and in the end, pay for the privilege of use. For something that is touted as being for all, financial requirements make it only for the rich and motivated. Thus another example of the rich getting richer and the poor getting poorer.

The matter of access to the equipment also raises more issues than it appears designed to solve. To begin with, it is a legitimate (if somewhat prescriptive) request that all students in a selective private school should have their own laptop computers with email accounts. To the students of Collingwood or Marrickville Girls High Schools (for instance), this is another matter. Even if the promise of the Government to fund the provision of such equipment, the cost to such lower socioeconomic secondary schools would be prohibitive. Also there is no consideration of the costs in maintenance of equipment (eg. system failures, equipment damage and viruses, etc.), let alone the upgrading of software.

The change rate of software is something in the order of twelve to eighteen mouths, and this may be erring on the conservative side. Also the costs of access into ISDN lines - an area which Telstra/Telecom is making a mint on - makes access to the less financially able even more remote.

There is a spin-off (for the moment). Students who have been brought up on laptops are required to think and write for their HSC and School Certificate examinations. The change in information presentation, on anecdotal evidence, could have a detrimental effect on the measured outcomes of the students comes. Maybe - for the moment - a fine example of the Law of Compensation in action.

However, the information access capacity for those attached to the Net means that they have access to a greater range of sources (as indicated at the beginning of the paper) and implicitly have a greater knowledge base to draw from in their presentation of information, within the examination structure. Whilst their hand may not be able to present it with the speed that it usually does, the knowledge gained through this active learning has a greater potential to stick than mere reading research may at present. The educational structures of tertiary academic learning appear to be more directed to formalised research, rather than the searching and degrees of intellectual discrimination required to obtain maximum benefit from this resource. Given the mind of those who are using it, the sky, at least, is the limit. 
Then comes the effects of the information gained. The example of the student contacting the international experts touches this matter. Apart from the basic reason for contact, that is to both play with "the new toy" and to show how "clever they are", the capacity to achieve and the knowledge acquired places the student in a situation of knowing more than their teacher (perhaps). This alone can effect the way the student views the knowledge and its use. The information itself could broaden the understanding, but to achieve what?

The capacity of the teacher, once capable of either controlling information by leaving it up on the black board or varying the rate of dictation (Yes, I know this ought to show my age... but), now to control what is being learned, is becoming increasingly diminished. Whether this is a good thing or not may be debated, but only in terms of the capacity to appreciate, rather than whether the experience ought to occur. Given the nature of the technology, ought ... is no longer an option. Given the capacity of the PC and the circumstance, contact can be made with whoever is out there.

A conclusion, albeit a hasty one, is that the role of the information coordinator (for want of better), rather than information dispenser is to motivate the students to increase the search, with a view to self discovery rather than trying to replicate existing knowledge. This presents educational institutions with the dilemma of being able to regulate what is studied and what can be seen to be known. It is no longer possible, I contend, given the previous arguments to compartmentalise knowledge and not allow a degree of inter-relativity to exist.

This dilemma manifests itself with concerns about access to pornography on "the Net". Or "gate-crashing" the CIA/ FBI data base. Fear of the "might be known" does not address the matter of the knowing. Would not a greater degree of exposure insure that there would be a greater degree of maturity in this matter? The matter of choice only comes from experience, and experience has to be seen a something that either be of quality or of indulgence.

The breadth of information now available seems to have slowed the search for new knowledge and to focus the mind on the known. As the access to information increases, perceptions change and what is considered necessary to know is reviewed. The need to determine relevance though falls into the matter of curriculum frame factors. What can be known, versus what can we know? Given that there is no more accessible fonts of knowledge, the main role of the pedagogue is to anticipate, direct and respond. Until the understanding becomes evident, information is acquired for its own sake, and new knowledge takes a back seat to the expansion process, and the increased levels of superficiality that this brings.

And yet the nature of the connoisseur can only occur through intelligent choices. These choices were made with reference to established parameters 
of taste. I would suggest that these parameters are only now being developed, and those that exist are based on the reference to existing knowledge, rather than an acknowledgment and appreciation of the new.

The problem's resolution requires an understanding of the nature of change, and that comes with experience. Barriers to involvement include the network owners' (Telstra, etc.) avarice in keeping charges at present levels. There appears to be little effort to reduce access prices or expand services to encourage the expansion of the service that would be of benefit to all users. The additional spin off of course being that profits would increase via economies of scale, the positive benefits that can occur are outweighed by the lack of access and the inequity of the rich being able to become more knowledgeable (although not necessarily smarter), at the expense of those less able to get and use this information.

The new telecommunications networks have arrived, and they are being used within secondary and tertiary education organisations. This presents the managers of learning with problems of information coordination, relevance and control. This can be addressed through a change of strategy, where knowledge provider strategies are replaced by other strategies in which knowledge is of joint ownership and is expanded through joint activities.

The relevance of the information being determined more by its utility, rather than by immediate societal demands. Education should move from this developing intellect focus, to the emotional and social focus, thus allowing for the student and the "teacher" to enjoy and use the knowledge rather than record its existence.

This situation however will remain a hope rather than a goal, given the lack of vision of the hardware suppliers and network managers to provide the necessary level of access, which would be needed to both bring the demand to its optimum, and allow for options to addressed, and an equity of information access to remain.

This new world of information accessibility places more responsibility on the learner than ever before. The principles of "self instruction" and "empowerment" require the learner to develop self understandings that will allow for most effective use of the resources, rather than "junking out" on the system - more than just "surfing" but building the waves.

The nature in which knowledge will be presented will require increased interpretive skills as well as an appreciation of the present as well as the discovered or developed understanding. It will be no longer possible to limit what content areas are, and to claim some element of philosophical exclusivity. Content will change in accord with the seeker, and it is the seeker's responsibility to ensure that its relevance and its association are seen within the defined context, so that the knowledge and the understandings that flow are more than merely chaff on the wind. 
The "new order" requires both an isolation and cooperation. The learning becomes active, and individual, yet with the greater access to knowledge, becomes a combined effort. This contradiction is another matter that needs resolution, and only with an increased understanding of these new resources can these issues be addressed.

I am not proposing major answers to questions I merely highlight. I think it is important to admit the existence of these changes so that means may developed to resolve and, in so doing derive benefit for all who need to use them.

\section{References}

Roberts, G. (1993). Educational technology and the mass lecture: A restatement of fundamental issues. Australian Journal of Educational Technology, 9(2),182-187. http: / / www.ascilite.org.au/ajet/ajet9/ roberts.html

Loader, D. (1994). The stumble principal and the vanishing classroom: An epic in real time. LETA '94 [audio tape].

Stuebings, S. (1994). Designing for Future Learning Environment. OECD/PAB Report, 1994.

Marriott, P. and Brittain, M. (1994). InfoTrain: An international electronic training journal. In J. Steele and J. G. Hedberg (eds), Learning Environment Technology: Selected papers from LETA 94, 161-162. Canberra: AJET Publications. http: / / www.ascilite.org.au/aset-archives / confs/edtech94/mp/marriott.html

Peter Blakey is presently the Production Coordinator for the Library and Media Services Unit of the Australian Catholic University - NSW Division. The Australian Catholic University is located in Victoria, New South Wales, Queensland and the ACT. He may be contacted at Australian Catholic University, 179 Albert Road, Strathfield, NSW 2135. Voice (02) 739 2142; Fax (02) 7392281. Email P.Blakey@mary.acu.edu.au.

Please cite as: Blakey, P. (1996). Education, media and the locus of control. Australian Journal of Educational Technology, 12(1), 18-24. http:/ / www.ascilite.org.au/ajet/ajet12/blakey.html 